\title{
Fish/corn oils modulate inflammatory mediators in DSS-induced ulcerative colitis
}

\author{
Eman I. Kandil ${ }^{1}$, Nashawa K. Ibrahim ${ }^{2}$, Dina E. El Shazaly ${ }^{1 *}$ and Fatma S. M. Moawed ${ }^{2}$ \\ ${ }^{I}$ Biochemistry Department, Faculty of Science, Ain Shams University, Cairo, Egypt, \\ ${ }^{2}$ National Center for Radiation Research and Technology, Atomic Energy Authority, Cairo, Egypt
}

\section{A R T I C L E I N F O}

Article history:

Received 10 January 2017

Accepted 01 March 2017

Keywords:

Ulcerative colitis;

FO/CO oils mixture;

$T N F-\alpha$;

IL-10;

$N F-\kappa B$;

STAT-3.

\begin{abstract}
A B S T R A C T
Excessive $n-6$ polyunsaturated fatty acids (PUFA) and inadequate n-3 PUFA have been associated with enhanced risks for developing ulcerative colitis (UC). In rodent models, n-3 PUFAs have been shown to either attenuate or exacerbate colitis in different studies. However, little information is available concerning the in vivo effects of these fatty acids on proinflammatory mediators. The aim of this study was to examine the effect of fish and corn oils mixture (FO/CO) on dextran sulfate sodium (DSS)-induced colitis in rats. Anti-inflammatory activity was assessed by colonic myeloperoxidase (MPO) and serum alkaline phosphatase (ALP) activities. Expression of inflammatory related mediators (iNOS, NF- $\kappa \mathrm{B}$ and STAT-3) and cytokines (TNF- $\alpha$ and IL-10) in serum were assessed. Our results demonstrated that $\mathrm{FO} / \mathrm{CO}$ mixture has anti-inflammatory properties by the reduced ALP and MPO activities. In addition, administration of FO/CO mixture for four weeks resulted in a decrease of inflammatory mediators; iNOS, NF- $\mathrm{kB}$ and STAT-3 accompanied with an increase of IL-10 level. Histopathological finding supported the obtained biochemical data. Therefore, administration of FO/CO mixture exerts the anti-inflammatory activity in rat model of DSSinduced colitis by inhibiting TNF- $\alpha$, iNOS, STAT-3 and NF- $\kappa$ B pathway associated with enhancement of IL-10.
\end{abstract}

\section{Introduction}

Ulcerative colitis (UC) is a subtype of the inflammatory bowel diseases (IBD) that affect gastrointestinal tract. UC causes chronic and remitting inflammation mainly in the mucosa and submucosal layer of the colon and rectum. The disease is characterized by impairment in intestinal integrity, accompanied by increase in inflammatory cells infiltration with increased production of pro-inflammatory mediators that are associated in further inflammation that may developed in long chronic cases into colon rectal cancer ${ }^{[1]}$. The exact mechanism of disease pathogenesis is not fully elucidated yet, as many factors are associated, thus, it is thought to be a multifactorial disease, which make it difficult to found a strong specific treatment for it ${ }^{[2]}$.

Increasing attention has been given to the role of diet and the increasing intake of n-6 polyunsaturated fatty acids (PUFA) in the modern diet to the increased incidence of the disease, the unbalanced ratio of (n-6: n3 ) that has been found in modern diet has been linked to be one of the factors that increased the risk of the

* Corresponding author.

E-mail address: dinaelsaeed@live.com inflammatory diseases including $\mathrm{UC}^{[3]}$.

It was reported that fish oil is rich in omega 3 fatty acids (n-3 FA) that exert a potent anti-inflammatory and antioxidant effect via reduction of pro-inflammatory mediators; tumor necrosis factor alpha (TNF- $\alpha$ ); myeloperoxidase (MPO) and inducible nitric oxide synthase (iNOS); as well as down regulating the expression of the transcription factors, nuclear factor kappa-B (NF- $\kappa \mathrm{B})$ and signal transducer and activating transcription (STAT-3). Unlike fish oil, corn oil is rich in omega 6 fatty acids (n-6 FA) that is highly found in modern diet, which plays a pro- inflammatory role in many inflammatory diseases ${ }^{[4]}$.

Therefore, the present study was conducted to elucidate the intestinal anti-inflammatory mechanism of corn oil, with fish oil- derived (n-3) PUFA in ratio 1: 2.5 respectively, in the DSS model of rat colitis; an experimental model of intestinal inflammation that has some histological and biochemical features of the human disease ${ }^{[5]}$. Special attention was paid to the effects exerted by these lipid manipulations on the production of some of the mediators involved in the inflammatory response. 


\section{Materials and methods}

Chemicals and reagents

Fish oil (FO) (density $=0.93 \mathrm{~g} / \mathrm{ml}$ at $25^{\circ} \mathrm{C}$ ), corn oil (CO) $\left(\right.$ density $=0.9 \mathrm{~g} / \mathrm{ml}$ at $\left.25^{\circ} \mathrm{C}\right)$ and dextran sulphate sodium (DSS) (average molecular weight $>500,000$ ) were obtained from Sigma Chemical Co., Nasr City, Cairo, Egypt. All other chemicals and reagents used in this study were of analytical grade.

\section{Animals}

Pathogen-free adult male Swiss albino rats weighing $200 \pm 20 \mathrm{~g}$ obtained from the Nile Pharmaceutical Co., Cairo, Egypt, were housed in standard plastic cages. The rats were naïve to DSS and fish oil/corn oil. Rodents were maintained with free access to standard laboratory pellet chow and water ad libitum. Rats were kept in the laboratory under controlled conditions of temperature $\left(27 \pm 2^{\circ} \mathrm{C}\right)$ and humidity $(60 \pm 5 \%)$ with $12 \mathrm{~h}$ light/12h dark cycles in well ventilated cages. All the experimental procedures were carried out according to the principles and guidelines of the Ethics Committee of the National Research Centre conformed to "Guide for the care and use of laboratory animals" for the use and welfare of experimental animals, published by the US National Institutes of Health (NIH publication No. 85-23, 1996).

\section{Experimental design}

The rats were acclimatized for 7 days and then separated into four groups each of six rats.

Groups are: group (1):control group, group (2) DSS group, rats fed 5\% (w/v) DSS in their drinking water for 8 days, according to Stucchi et al., ${ }^{[6]}$, group (3): FO/CO group, the animals of this group were given $\mathrm{FO} / \mathrm{CO}$ mixture in ratio 2.5:1 for four weeks $(0.5 \mathrm{ml}$ of $\mathrm{FO} / \mathrm{CO}$ mixture/day/rat) by oral gavage, group (4): DSS + FO/CO group, rats were fed $5 \%(\mathrm{w} / \mathrm{v})$ DSS as in group 2 then orally administrated $\mathrm{FO} / \mathrm{CO}$ mixture as in group (3). At the end of the experiment, the rats, which were food deprived for $24 \mathrm{~h}$, were anesthetized by light ether. Thoracotomy, cardiac puncture and exsanguination were then performed. Blood samples were collected and serum were separated and stored at $-20 \mathrm{C}^{0}$ pending analyses. A midline abdominal incision was performed in each animal and colon were collected terminally from rats in different groups, flushed with sterile phosphate-buffered saline and dried carefully.

\section{Biochemical assays}

Alkaline phosphatase (ALP) activity in serum was determined as described by Young et al. ${ }^{[7]}$, using a kit purchased from Biometra Co. (Egypt). Colonic myeloperoxidase enzyme (MPO) was detected through colorimetric assay by Northwest NWLS (USA) according to Kettle and Winterbourn ${ }^{[8]}$. Levels of tumor necrosis factor $\alpha$ (TNF- $\alpha$ ) and interleukin 10 (IL10) in distal colon were determined by using the corresponding ELISA kit following protocols provided by the manufacturers Boster (USA).

\section{Western immunoblotting}

Colon tissue proteins were extracted using TRIzol reagent, and protein concentrations were quantified by Bradford method ${ }^{[9]}$. Twenty $\mu \mathrm{g}$ of protein per lane were separated with $10 \%$ SDS-PAGE and transferred onto
PVDA membranes. The membranes were incubated at room temperature for $2 \mathrm{~h}$ with blocking solution comprised of $5 \%$ nonfat dried milk in $10 \mathrm{mM}$ Tris-Cl, $\mathrm{pH} 7.5,100 \mathrm{mM} \mathrm{NaCl}$, and $0.1 \%$ Tween 20, then incubated overnight at $4{ }^{\circ} \mathrm{C}$ with the primary antibodies towards ERK and PI3K with $\beta$-actin as loading control. After washing three times in $10 \mathrm{mM}$ Tris-Cl, $\mathrm{pH} 7.5,100$ $\mathrm{mM} \mathrm{NaCl}$, and $0.1 \%$ Tween 20 , membranes were incubated with the secondary monoclonal antibodies conjugated to horseradish peroxidase at room temperature for $2 \mathrm{~h}$, and then membranes were washed four times with the same washing buffer. Mmembranes were developed and visualized by chemiluminescence using Amersham detection kit according to the manufacturer's protocols, then exposed to X-ray film. Primary and secondary antibodies were purchased from Cell Signaling Technologies, USA. Quantification of STAT-3 protein was performed by densitometric analysis of the autoradiograms using a scanning laser densitometer (Biomed Instrument Inc., USA). Results were expressed as arbitrary units after normalization for $\beta$-actin.

Detection of inducible nitric oxide synthase and nuclear factor kappa $B$ by quantitative real time PCR (qRT-PCR)

\section{RNA Isolation and Reverse Transcription}

To investigate the changes in mRNA expression for (NF$\kappa \mathrm{B})$ and inducible nitric oxide synthase (iNOS) according to Pfaffl ${ }^{[10]}$, total RNA was isolated from $100 \mathrm{mg}$ colon using TRIzol reagent in accordance to the manufacturer's instructions (Life Technologies, USA). RNA integrity was confirmed by $1 \%$ agarose gel electrophoresis and stained with ethidium bromide. First strand ccomplementary DNA (cDNA) synthesis was performed with reverse transcriptase (Invitrogen) according to the manufacturer's protocol using $1 \mu \mathrm{g}$ of total RNA as the template.

\section{Quantitative Real-time polymerase chain reaction (qRT-PCR)}

RT-PCRs were performed in a thermal cycler step one plus (Applied Biosystems, USA) using Sequence Detection Software (PE Biosystems, CA) according to Pfaffl ${ }^{[10]}$. A reaction mixture of total volume $25 \mu \mathrm{l}$ consisting of $2 \mathrm{X}$ SYBR Green PCR Master Mix (Applied Biosystems), $900 \mathrm{nM}$ of each primer and $2 \mu \mathrm{L}$ of cDNA. The sequences of PCR primer pairs used for each gene are as follows, NF-кB: Forward: F: 5'GCTTACGGTGGGATTGCATT-3', Reverse: R:5'TTATGGTGCCATGGGTGATG-3', iNOS: Forward: 5'GGG CCA CCT TTA TGT TTG TG-3', Reverse: 5'CCG GTG GGT TTC TTC TTC TTG AA- $3^{\prime}, \beta$-actin: Forward: 5'-ATG GGA GTT GCT GTT GAA GTC A3', Reverse: 5'-CCG AGG GCC CAC TAA AGG-3'. The PCR thermal-cycling conditions included an initial step at $95^{\circ} \mathrm{C}$ for $5 \mathrm{~min} ; 40$ cycles at $95^{\circ} \mathrm{C}$ for $20 \mathrm{~s}, 60^{\circ} \mathrm{C}$ for $30 \mathrm{~s}$, and $72^{\circ} \mathrm{C}$ for $20 \mathrm{~s}$. Curve analysis was performed at the end of the reaction. The data were normalized using the $\beta$-actin gene that was amplified in each set of PCR experiments. 
Relative expression of target mRNA was calculated using the comparative $\mathrm{Ct}$ method of Pfaffl ${ }^{[10]}$. Each experiment was performed in triplicate in two independent experiments.

\section{Histopathological assessment}

Entire colons were stored in histology cassettes immersed in $10 \%$ neutral buffered formalin and fixed in $10 \%$ formal saline for 24 hours. Washing was done in tape water then serial dilutions of alcohol (methyl, ethyl and absolute ethyl) were used for dehydration. Specimens were cleared in xylene and embedded in paraffin at 56 degree in hot air oven for 24 hours. Paraffin bees wax tissue blocks were prepared for sectioning at 4-micron thickness by slide microtome. The obtained tissue sections were collected on glass slides, deparaffinized and stained by hematoxylin and eosin $(H \& E)$ stain for routine examination through the light electric microscope.

\section{Statistical analyses}

All data were expressed as the mean \pm SE. One-way analysis of variance (ANOVA) with Least Significant
Difference (LSD) was used to test for differences in means of variables between groups. A probability of $P<0.05$ was considered significant. All data were analyzed by Statistical Package for Social Science (SPSS) version 20 for Windows (SPSS $^{\circledR}$ Chicago, IL, USA) software program.

\section{Results}

\section{Biochemical analyses}

Treatment of animals with DSS induced ulcerative colitis throughout the significant increase in colonic activity of MPO, serum ALP activity and colonic TNF- $\alpha$ level with the concomitant significant decrease in the colonic IL-10 level in comparison with both controls and FO/CO treated groups. Administration of $\mathrm{FO} / \mathrm{CO}$ showed statistically significant improvement versus the colitis group (Fig. 1).

\section{Western immunoblotting}

DSS treatment induced marked significant higher level of the signal transducer and activator of transcription-3: STAT-3. Administration of FO/CO showed statistically significant improvement versus the colitis group.

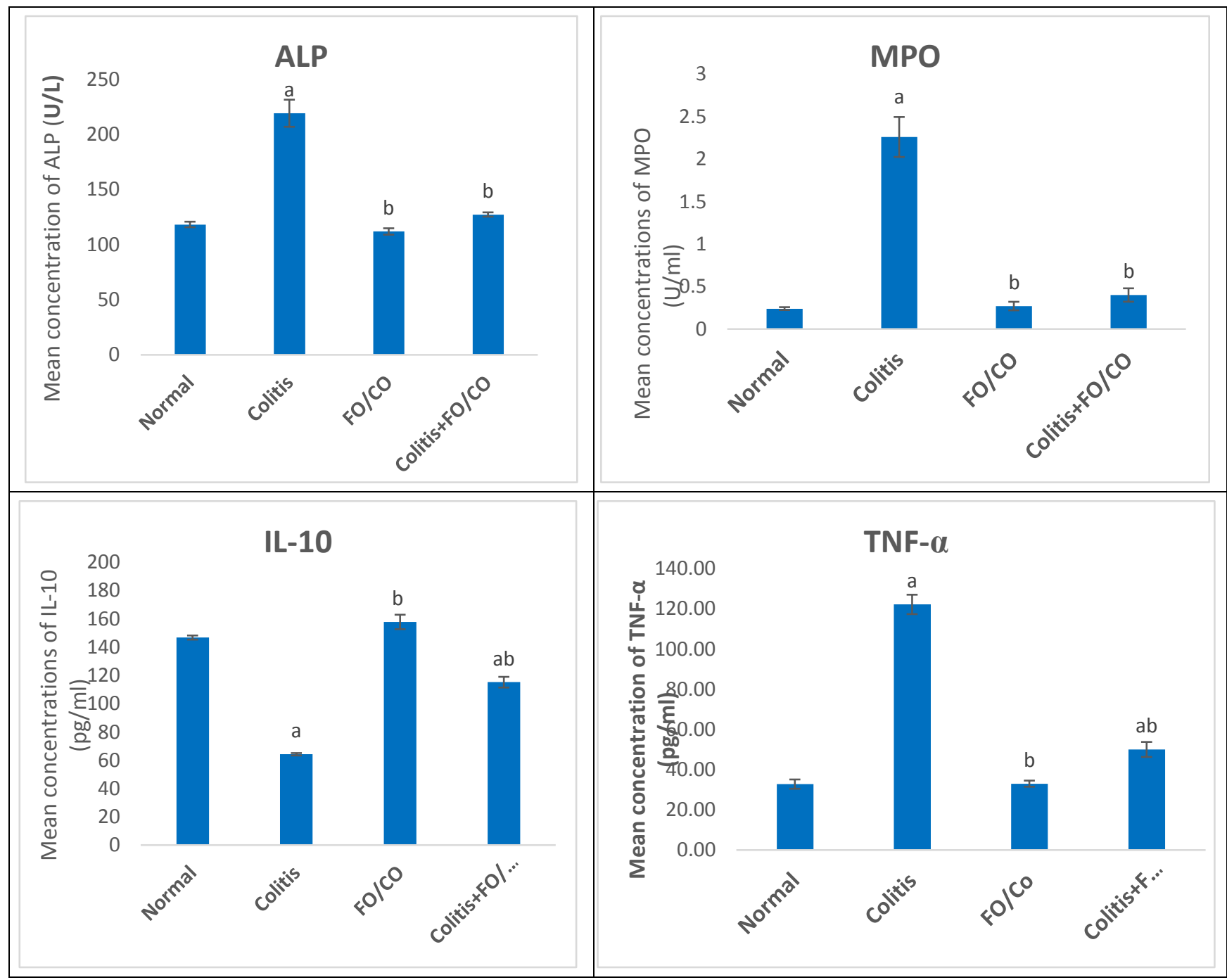

Fig (1): ALP, MPO, IL-10 and TNF- $\alpha$ level in different groups compared with controls. Each column represents mean \pm SE $(n=6) .{ }^{a} \mathrm{P}<0.05$ compared to control; ${ }^{b} \mathrm{P}<0.05$ compared to colitis group. 


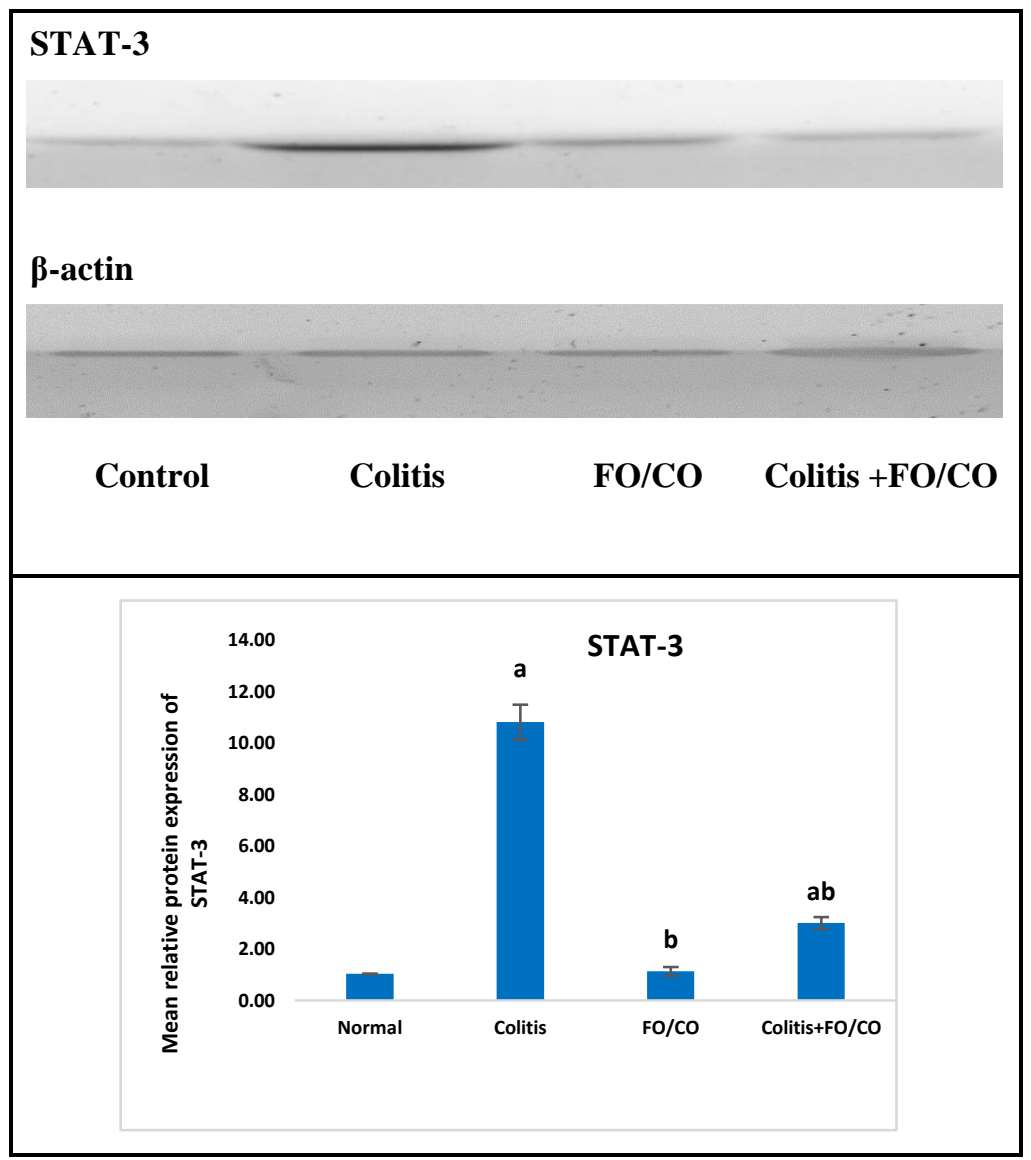

Fig (2): Western immunoblotting analysis of STAT-3 protein expression. Each bar represents mean $\pm \mathrm{SE} ;{ }^{\mathrm{a}} \mathrm{P}<0.05$ compared to control; ${ }^{\mathrm{b}} \mathrm{P}<0.05$ compared to DSS group.

\section{qRT-PCR for NF- $\kappa B$ and iNOS}

Expressions of NF- $\kappa b$ and iNOS genes were analyzed by RT-PCR. The transcript levels of NF- $\kappa B$ protein and iNOS genes were significantly higher in DSS-treated group (Fig. 3) in comparison with controls. In the treatments using $\mathrm{FO} / \mathrm{CO}$ only, this transcript did not show any significant difference in the levels from controls. However, after treatment of colitis with $\mathrm{FO} / \mathrm{CO}$, the transcript level of these genes was significantly lower than that in the DSS-treated animals.

\section{Histopathology}

Colon tissues either for control or $\mathrm{FO} / \mathrm{CO}$ rat groups showed no histopathological alteration and normal histological structure of the mucosa (Fig. 4A \& C). Colon tissues with DSS treatment group showed massive numbers of inflammatory cells infiltration in the mucosa and underlying submucosa (Fig. 4B). In Colitis + FO/CO group, colon tissues showed few inflammatory cells infiltration in the lamina propria of the mucosal layer (Fig. 4D).

\section{Discussion}

The current study was conducted to understand the antiinflammatory action of $\mathrm{FO} / \mathrm{CO}$ on the inflammatory mediators in DSS induced ulcerative colitis (UC). This colitis model is widely applied for screening of drugs for treatment of UC because of its high similarity to human $\mathrm{UC}$; also DSS-induced colitis is one of the most suitable experimental models ${ }^{[5]}$.

A previous study has demonstrated the importance of modulating the $\oplus-6: \Phi-3$ ratio to obtain beneficial effects rather than simply reducing $₫-6$ PUFA levels ${ }^{[11]}$. The study conducted by Kansal et al. ${ }^{[12]}$ has demonstrated that $\mathrm{FO} / \mathrm{CO}(2.5: 1)$ has better chemo-preventive efficacy as compared to $\mathrm{FO} / \mathrm{CO}(1: 1)$ in experimentally induced colon cancer. Accordingly, in the present study, we administrated $\mathrm{FO} / \mathrm{CO}$ oils in ratio of 2.5:1 respectively in induced colitis.

In this model of DSS induced colitis, intestinal inflammation has been proved biochemically by increasing in colonic MPO and serum ALP activities. MPO is an enzyme found in neutrophils and monocytes, its activity is considered as a marker of neutrophil infiltrations into the colon, upon activation, MPO is released and catalyzes the formation of potent oxidants that contribute to tissue damage ${ }^{[13]}$. In consistent with reports by Barros et al. ${ }^{[14]}$ and Nagib et al. ${ }^{[15]}$, significant increase in MPO activity after DSS administration has been shown in this study, suggesting the recruitment of leukocytes. Similarly, ALP is an enzyme which has been used to determine the degree of injury and inflammation in intestinal tissues ${ }^{[16]}$ also has been increased, a result related to the results of Camuesco et al. ${ }^{[11]}$. 
Inflammation was also assessed by measuring proinflammatory mediators, such as inflammatory cytokines and chemokines that are further controlled by the activity of transcriptional factors. In UC, immune cells including $\mathrm{T}$ lymphocytes and macrophages secrete inflammatory cytokines in the inflammation site. These activated cells modulate the balance between pro- and anti-inflammatory cytokines. In the present study, DSS caused overproduction of mediators involved in intestinal inflammatory response TNF- $\alpha$, iNOS and transcription factors (NF- $\mathrm{KB}$ and STAT-3) that contributed in exacerbation of inflammatory process, while inhibited production of anti-inflammatory mediator (IL-10) that control the inflammatory process. Many studies had demonstrated the role of IL-10 in maintenance of epithelial homeostasis. IL-10 is an immunoregulatory cytokine that influence both innate and cell-mediated immune response ${ }^{[17]}$.

An increase in transcription factor NF- $\kappa B$ activity that has been demonstrated in this study has been linked to increased levels of inducible nitric oxide synthase (iNOS) used as indicative parameter for increased level of oxidative stress. It is believed that iNOS levels increase during chronic inflammation as a consequence of oxidative stress process and the further release of reactive oxygen species (ROS). Continuous exposure to (ROS) may cause damage in the epithelial cells DNA, triggering the appearance of genetic mutations and initiating colorectal carcinogenesis ${ }^{[18]}$. Previous studies also reported that TNF- $\alpha$ and iNOS increase during DSS treatment and during intestinal inflammation and this increase was thought to be associated to many symptoms of UC and may contribute to the damage occurring in mucosal and submucosal cells of intestine ${ }^{[17,18]}$.
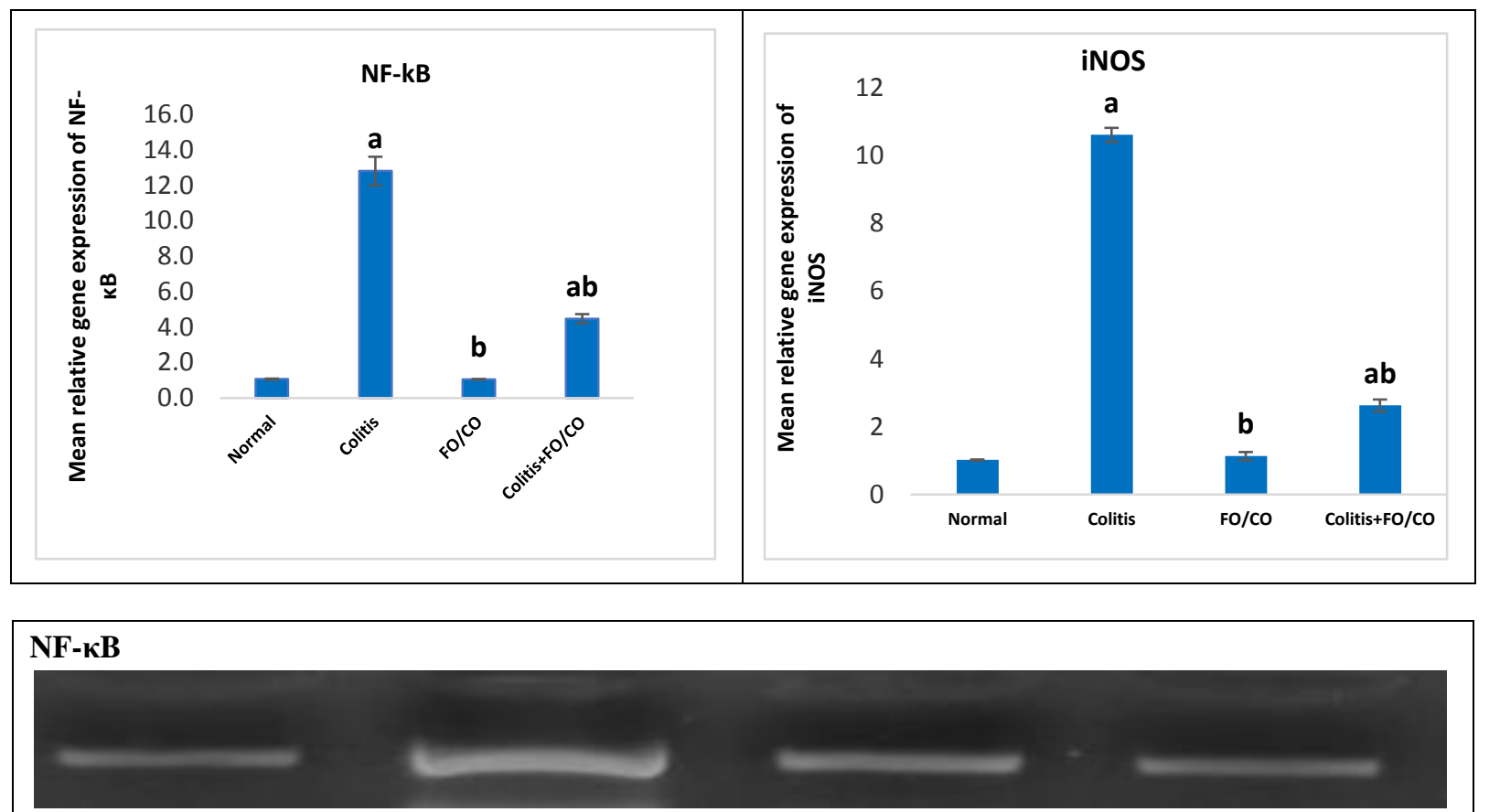

\section{iNOS}

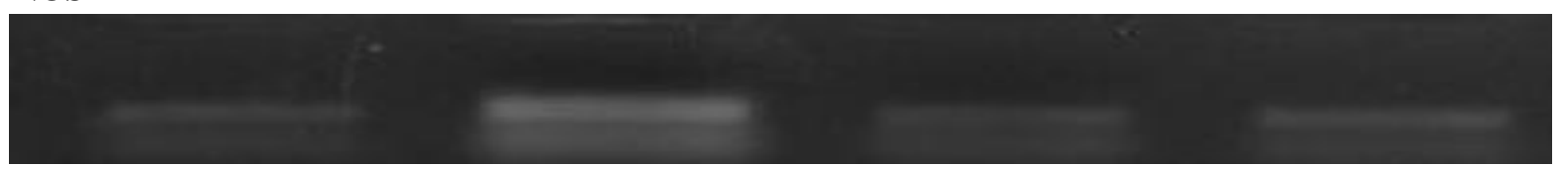

\section{$\beta$-actin}

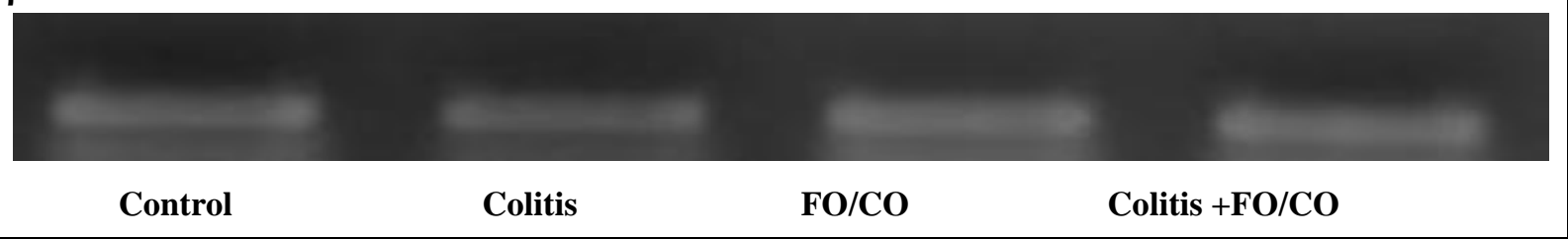

Fig (3): Effect of FO/CO upon DSS- induced alteration in mRNA expression of NF-kb and iNOS expressed as relative quantification compared to the control group assigned a value of unity using quantitative RT-PCR analysis. Each bar represents mean \pm SE. ${ }^{\mathrm{a}} \mathrm{P}<0.05,{ }^{\mathrm{b}} \mathrm{P}<0.05$ compared to DSS group. 


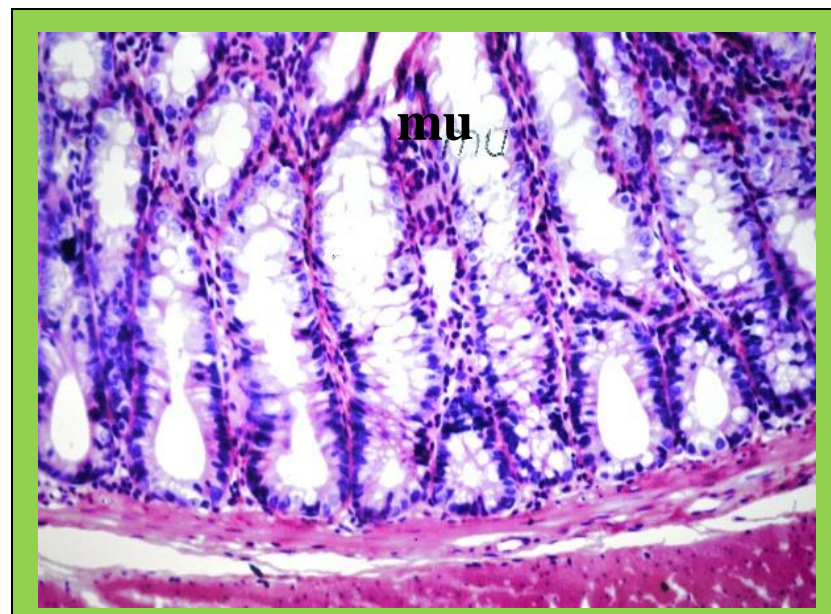

(A)

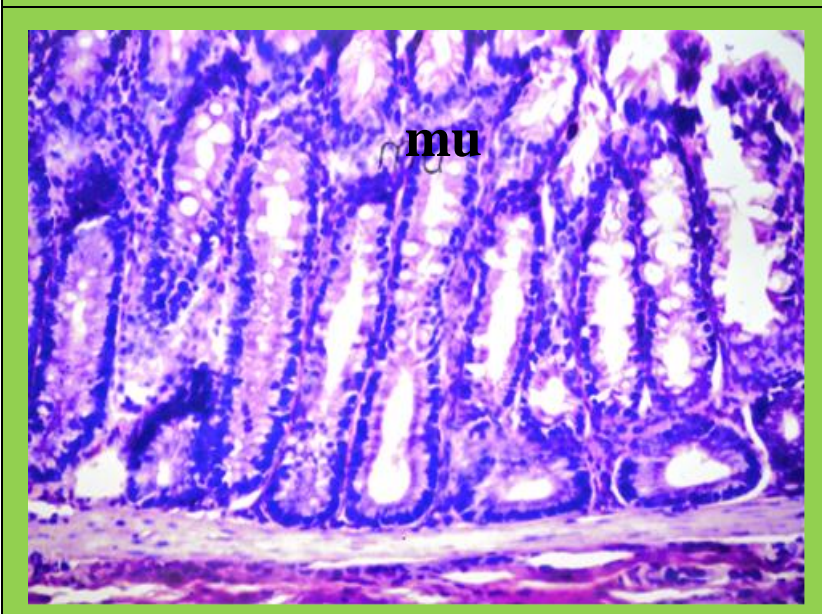

(C)

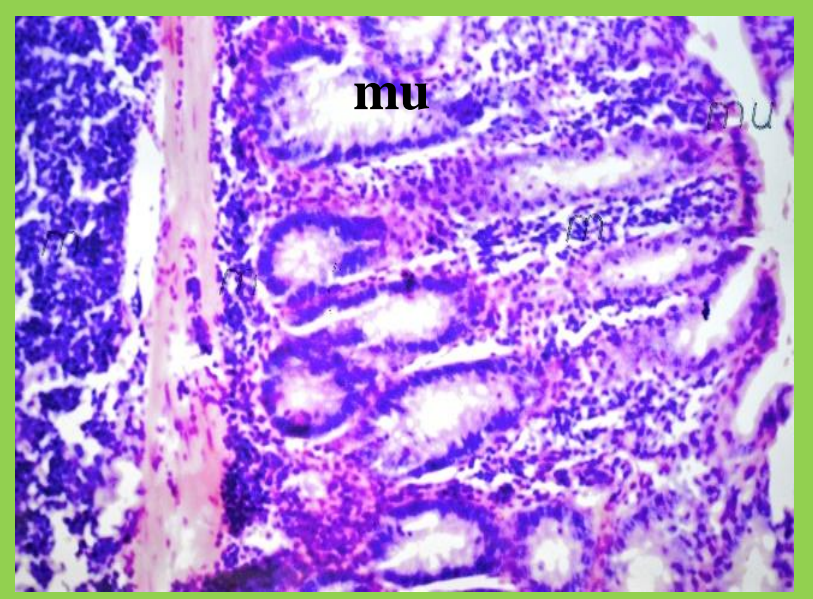

(B)

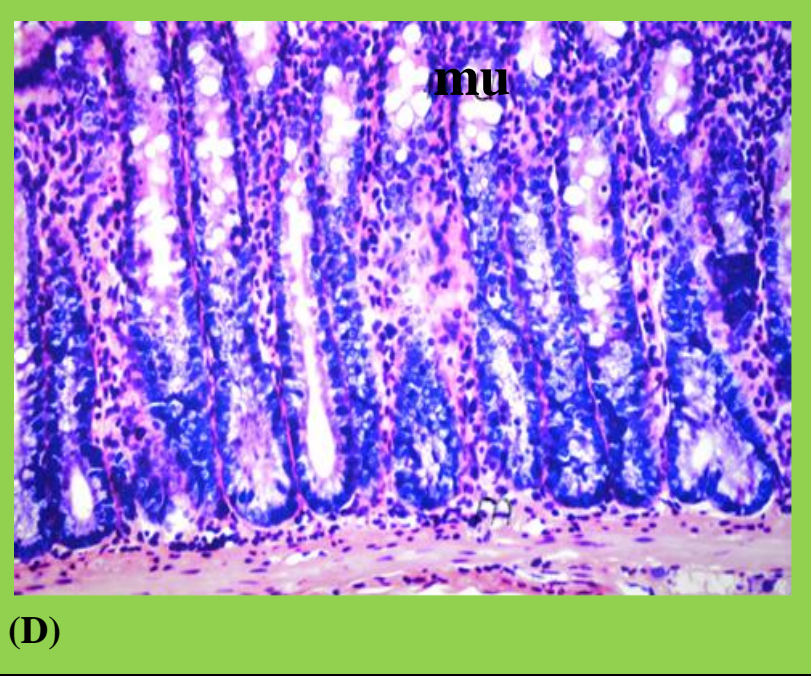

Fig (4): Photomicrographs of colon specimens stained with haematoxylin and eosin showing:

(A) The normal histological structure of the mucosa (mu) was recorded in normal rats. (B) Massive numbers of inflammatory cell infiltrations were detected in the mucosa and underlying submucosa in colitis rats. (C) No histological alteration in FO/CO administrated rats. (D) Few inflammatory cell infiltrations were noticed in the lamina propria of the mucosal layer in Colitis + FO/ CO.

The role of STAT3 in intestinal inflammation is being supported by the fact that activated STAT3 has been found in human inflammatory bowel disease and animal colitis models ${ }^{[19]}$. High STAT3 activity and expression have been shown to correlate with disease activity in patients with IBD. Hence, there is a special interest in targeting STAT3 for the treatment of IBD ${ }^{[20]}$. A study by Musso et al. ${ }^{[21]}$ has proved that activated STAT3 is present in the mucosa of UC patients which indicate that it is critically involved in gut inflammation and may become a novel therapeutic target. Consistent with previous study ${ }^{[22]}$, we observed an increased expression of STAT-3 in DSS-induced rats.

On the other hand, in this study, administration of FO/CO mixture had showed an anti-inflammatory effect approved by significant decrease in activity of proinflammatory markers; TNF- $\alpha$, MPO and iNOS and inhibition in the activity of NF- $\mathrm{KB}$. These findings are in agreement with a previous study reporting attenuation in inflammatory markers levels as an effect of fish oil in induced colitis model ${ }^{[23]}$. The results also indicated the significant beneficial effect of $\mathrm{FO} / \mathrm{CO}$ oils in association with reduced STAT3 activation in UCinduced rats. One mechanism to explain the effect of n-3 FA in mixture with n-6 FA is the competition role of fish oil that prevents conversion of arachidonic acid (AA) to pro-inflammatory eicosanoids by the cyclooxygenase or lipoxygenase enzymes when (EPA) and (DHA) replace (AA) and inhibit production of pro-inflammatory mediators ${ }^{[24]}$.

In conclusion, $\mathrm{FO} / \mathrm{CO}$ oils significantly modulate $\mathrm{MPO}$ activity and reduce iNOS level. In addition, FO/CO oils decreased the secretion of proinflammatory cytokine; $(\mathrm{TNF}-\alpha)$, and increased the secretion of antiinflammatory cytokine, (IL-10); FO/CO oils were also

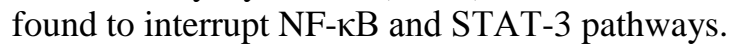




\section{References}

1) Uranga, J. A., López-Miranda, V., Lombó, F. and Abalo, R. (2016). Food, nutrients and nutraceuticals affecting the course of inflammatory bowel disease. Pharmacol. Reports. 68:816-826.

2) de Souza, H. S. P. and Fiocchi, C. (2016). Immunopathogenesis of IBD: current state of the art. Nat. Rev. Gastroenterol. Hepatol. 13:13-27.

3) Bosco, N., Brahmbhatt, V., Oliveira, M., Martin, F. P., Lichti, P., Raymond, F., Mansourian, R., Metairon, S., Pace-Asciak, C., Bastic Schmid, V., Rezzi, S., Haller, D. and Benyacoub, J. (2013). Effects of increase in fish oil intake on intestinal eicosanoids and inflammation in a mouse model of colitis. Lipids Health Dis. 12:81.

4) Barbalhoa, S. M., Goulart, R. d., Quesadac, K., Becharad, M. D. and de Carvalho, A. de C. A. (2016). Inflammatory bowel disease : can omega-3 fatty acids really help? Ann. Gastroenterol. 29:3743.

5) Yan, Y., Kolachala, V., Dalmasso, G., Nguyen, H., Laroui, H., Sitaraman, S. V. and Merlin, D. (2009). Temporal and spatial analysis of clinical and molecular parameters in dextran sodium sulfate induced colitis. PLoS One. 10.1371/journal.pone.0006073.

6) Stucchi, A. F., Shofer, S., Leeman, S., Materne, O., Beer, E., McClung, J., Shebani, K., Moore, F., O'Brien, M. and Becker, J. M. (2000). NK-1 antagonist reduces colonic inflammation and oxidative stress in dextran sulfate-induced colitis in rats. Am. J. Physiol. Gastrointest. Liver Physiol. 279:G1298-306.

7) Young, D. S., Thomas, D. W., Friedman, R. B. and Pestaner, L. C. (1972). Effects of Drugs on Clinical Laboratory Tests. Clin. Chem. 18(10):10411303.

8) Kettle, A. J. and Winterbourn, C. C. (1994). Assays for the chlorination activity of myeloperoxidase. Methods Enzymol. 233:502-12.

9) Bradford, M. M. (1976). A rapid and sensitive method for the quantitation of microgram quantities of protein utilizing the principle of protein-dye binding. Anal. Biochem. 72:248-254.

10) Pfaffl, M. W. (2001). A new mathematical model for relative quantification in real-time RT-PCR. Nucleic Acids Res. 29:45e-45.

11) Camuesco, D., Gálvez, J., Nieto, A., Comalada, M., Rodríguez-Cabezas, M. E., Concha, A., Xaus, J. and Zarzuelo, A. (2005). Dietary olive oil supplemented with fish oil, rich in EPA and DHA (n-3) polyunsaturated fatty acids, attenuates colonic inflammation in rats with DSS-induced colitis. The Journal of nutrition, 135:687-694.

12) Kansal, S., Bhatnagar, A. and Agnihotri, N. (2014). Fish oil suppresses cell growth and metastatic potential by regulating PTEN and NF- $\kappa B$ signaling in colorectal cancer. PLoS One. 10.1371/journal.pone.0084627.

13) Laroui, H., Ingersoll, S. A., Liu, H. C., Baker, M. T., Ayyadurai, S., Charania, M. A., Laroui, F., Yan, Y., Sitaraman, S. V. and Merlin, D. (2012). Dextran sodium sulfate (dss) induces colitis in mice by forming nano-lipocomplexes with medium-chainlength fatty acids in the colon. PLoS One. 10.1371/journal.pone.0032084.

14) de Barros, K. V., Cassulino, A. P. and Silveira, V. L. F. (2012). Polyunsaturated fatty acids, ulcerative colitis and cancer prevention. INTECH Open Access Publisher. DOI: 10.5772/28859

15) Nagib, M. M., Tadros, M. G., Elsayed, M. I. and Khalifa, A. E. (2013). Anti-inflammatory and antioxidant activities of olmesartan medoxomil ameliorate experimental colitis in rats. Toxicol. Appl. Pharmacol. 271:106-113.

16) Nieto, N., Torres, M. I., Fernandez, M. I., Giron, M. D., Rios, A., Suarez, M. D. and Gil, A. (2000). Experimental ulcerative colitis impairs antioxidant defense system in rat intestine. Digestive diseases and sciences, 45(9):1820-1827.

17) Li, B., Alli, R., Vogel, P. and Geiger, T. (2013). IL-10 modulates DSS-induced colitis through a macrophage-ROS-NO axis. 10.1038/mi.2013.103.

18) Ribeiro, M. L., Priolli, D. G., Miranda, D. D. C., Arçari, D. P., Pedrazzoli, J. and Martinez, C. a R. (2008). Analysis of oxidative DNA damage in patients with colorectal cancer. Clin. Colorectal Cancer. 7:267-272.

19) Mudter, J., Weigmann, B., Bartsch, B., Kiesslich, R., Strand, D., Galle, P. R., Lehr, H. A., Schmidt, J. and Neurath, M. F. (2005). Activation pattern of signal transducers and activators of transcription (STAT) factors in inflammatory bowel diseases. Am. J. Gastroenterol. 100:64-72.

20) Coskun, M., Salem, M., Pedersen, J. and Nielsen, O. (2013). Involvement of JAK/STAT signaling in the pathogenesis of inflammatory bowel disease. Pharmacol. Res. 76:1-8.

21) Musso, A., Dentelli, P., Carlino, A., Chiusa, L., Repici, A., Sturm, A., Fiocchi, C., Rizzetto, M., Pegoraro, L., Sategna-Guidetti, C. and Brizzi, M. F. (2005). Signal transducers and activators of transcription 3 signaling pathway. An essential mediator of inflammatory bowel disease and other forms of intestinal inflammation. Inflammatory bowel diseases, 11(2):91-98.

22) Suzuki, A., Hanada, T., Mitsuyama, K., Yoshida, T., Kamizono, S., Hoshino, T., Kubo, M., Yamashita, A., Okabe, M., Takeda, K., Akira, S., Matsumoto, S., Toyonaga, A., Sata, M. and Yoshimura, A. (2001). Cis $3 /$ Socs $3 /$ Ssi3 plays a negative regulatory role in stat 3 activation and intestinal inflammation. J. Exp. Med. 193(4):471481. 
23) Huang, C. H., Hou, Y. C., Yeh, C. L. and Yeh, S. L. (2015). A soybean and fish oil mixture with different $n-6 / n-3$ PUFA ratios modulates the inflammatory reaction in mice with dextran sulfate sodium-induced acute colitis. Clin. Nutr. 34:10181024.
24) Shores, D. R., Binion, D. G., Freeman, B. A. and Baker, P. R. S. (2011). New insights into the role of fatty acids in the pathogenesis and resolution of inflammatory bowel disease. Inflammatory bowel diseases. 17:2192-2204. 